Hypernatraemia is a particularly dangerous form of electrolyte disturbance, ${ }^{19}$ since it tends to be self-perpetuating. The child becomes listless, irritable and increasingly reluctant to take the fluid so essential for recovery, while excretion of sodium is impaired by renal shutdown. This serious medical emergency is being detected with increasing frequency in babies with gastroenteritis; in one recent survey from Manchester more than $60 \%$ of the dehydrated babies had hypernatraemia on admission. ${ }^{20}$ Babies in India, in contrast, never seem to develop hypernatraemia, and $50 \%$ of those with gastroenteritis in one recent survey had hyponatraemia on admission. ${ }^{21}$ It is certainly tempting to assume, therefore, that the early introduction of a mixed diet has had something to do with the high incidence of hypernatraemia now seen both here and in America. If this assumption is correct, babies with gastroenteritis complicated by hypernatraemia might be heavier for their age than babies without complicating hypernatraemia, and this piece of epidemiological research would be worth undertaking. The use of a sodium-rich milk has been reported to increase the risk of hypernatraemia in gastroenteritis, 22 though no such association was established in one carefully conducted study, ${ }^{23}$ and epidemiological evidence that early mixed feeding increases the risk of frankly symptomatic hypernatraemia is not yet available.

The change to a weaning diet can be expensive, can increase the child's sodium intake by up to $50 \%$, and may increase the risk of early obesity. Parents are often warned not to change from powdered milk to fresh milk when a child is weaned, ${ }^{24}$ but there is a real risk of hypernatraemia at this stage if the milk is too concentrated. Since it is always difficult to distinguish between hunger and thirst in a young baby, all infants on a weaning diet need to be offered their fill of water twice a day. As a correspondent ${ }^{25}$ recently observed, "The commonest deficiency disease of babies in this country is lack of water."

1 Pan American Health Organization, Scientific Publication No. 251, Washington, 1972.

Shukla, A., Forsyth, H. A., Anderson, C. M., and Marwah, S. M., British Medical fournal, 1972, 4, 507.

Taitz, L. S., British Medical fournal, 1971, 1, 315.

Tanner, J. M., Whitehouse, R. H., and Takaishi, M., Archives of Disease in Childhood, 1966, 41, 454 and 613.

5 Moore, T., Hindley, C. B., and Falkner, F., British Medical fournal, 1954, 2, 1132 .

- Eid, E. E., British Medical fournal, 1970, 2, 74.

7 Asher, P., Archives of Disease in Childhood, 1966, 41, 672.

8 Brook, C. G. D., Lancet, 1972, 2, 624.

- Brook, C. G. D., Lloyd, J. K., and Wolff, O. H., British Medical fournal,

10 Lloyd, J. K., Wolff, O. H., and Whelen, W. S., British Medical fournal, $1961,2,145$.

11 Shaw, J. C. L., Jones, A., and Gunther, M., British Medical fournal, 1973,

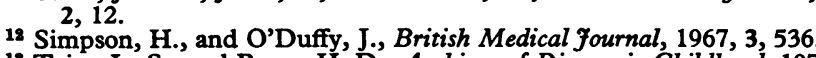

18 Taitz, L. S., and Byers, H. D., Archives of Disease in Childhood, 1972, 47, 257

14 Wilkinson, P. W., Noble, T. C., Gray, G., and Spence, O., British Medical Fournal, 1973, 2, 15.

16 Puyau, F. A. and Hampton, L. P., American Fournal of Diseases of Children, 1966, 111, 370.

16 Davies, D. P., British Medical fournal, 1973, 2, 348.

17 Polácek, E., Vocel, J., Neugebauerová, L., Sebková, M., and Vechetová, E., Archives of Disease in Childhood, 1965, 40, 291.

18 Aperia, A., Broberger, O., Thodenius, K., and Zetterstrom, R., Acta

19 Finberg, L., Advances in Pediatrics, ed. I. Shulman, vol. 16, p. 325.

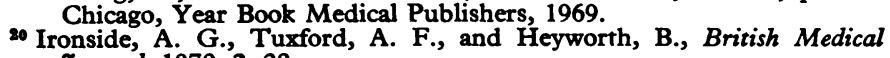
Fournal, 1970, 3, 20.

1 Kamlani, M., Bhat, P., Moses, A. K., Prasad Rao, and Webb, J. K. G., Fournal of the Indian Paediatric Society, 1963, 2, 341.

22 Colle, E., Ayoub, E., and Raile, R. Pediatrics, 1958, 22, 5.

23 Bruck, E., Abal, G., and Aceto, T. American fournal of Diseases of Children, $1968,115,122$ and 281 .

Scottish Home and Health Department, Principles of Infant Feeding Edinburgh, 1970.

2s Hughes-Davies, T. H., British Medical fournal, 1973, 1, 111.

\section{Auditory Perception}

In days gone by the tape measure, weighing scales, pin, tuning fork, and watch were the equipment available to assist the diagnostician who felt moved to measure. Now medical measurement is an expanding discipline.

Over the past 25 years great advances have been made in the assessment of hearing loss. No modern otolaryngological department or school health authority could function without a pure tone audiometer. This instrument enables a person's hearing to be compared with a theoretical norm-that is, with the average response of a large number of healthy young adults. A slightly more sophisticated instrument enables the audiologist to divide loss of hearing into two main groups-sensorineural, formerly called nerve deafness, and conductive deafness. Before the arrival of such an instrument this distinction was inferred from the results of a series of tuning fork tests. More recently it has become possible to subdivide sensorineural deafness into two components and thus place a lesion anatomically in the sense organ or the neural pathway. Such tests require the cooperation of the patient and are therefore subjective. It would seem apparent that objective audiometry would offer great scope for further investigation, and the advent of electrical response audiometry and electro-cochleography are already opening up exciting prospects for the future.

But the ability to test the integrity of the auditory pathway from the pinna to the cortex does not provide the audiologist with the answer to every problem. Children are often found who have normal audiological thresholds to pure tones and who have obvious perceptual difficulties. For example, they may learn to speak late or suffer from a speech difficulty or tone deafness, and because of this they may experience considerable educational handicaps. The handicaps are not related to the child's intellectual ability. Pure tone audiometry is of little help in these cases once it is established that the hearing is normal. Recently, J. A. M. Martin and Dorothy Martin reported a preliminary study of a test of the patient's ability to take a sound pattern and to integrate it into his sensorium. 1 They divide hearing into three levels. (1) The transference of sound waves into acoustical energy and transport along the auditory pathway to the brain; this may be tested by pure tone audiometry. (2) The ability to discriminate between sounds; hearing experience does not consist in the interpretation of pure tones of varying intensity but in the interpretation of complex impure tones which vary considerably in pitch, intensity, and rhythm. (3) The ability to identify and to recognize the sound heard. They consider that the third function needs to be investigated before progress can be made towards understanding the complex problems of children with normal hearing who acquire speech and language only with difficulty.

The first test used in this research employed a complex tone composed of a fundamental and two formant frequencies. The characteristics of the tones were constant except that alterations were made in the fundamental tone by making small changes in frequency. The composite sounds were meaningless. Sounds were then paired, and the test subjects (who were sixth-form schoolboys and therefore of similar academic ability) were asked to say whether the pairs were identical or different. The second test required the subject to compare the duration of pairs of sounds and to say whether they were identical or different. 
The final test asked the subject to compare rhythm. A constant drum beat was recorded with an accent on the first beat, and then "off" beats were added after the first, second, and third beats respectively. It was thus possible to construct pairs and again the subject was required to say whether the pair was identical or different.

The results of each of the three tests for 14 subjects were statistically analysed, and the results showed that there were significant differences in a normal person's ability to compare complex sounds, the length of sound, and the rhythm of sound. But, more than this, they showed that people differ in their ability to perceive sounds and sound patterns, so that one person may have no difficulty with some perceptual tasks and great difficulty with others. This is only a preliminary study and the problem is complicated, but the development of a standard test procedure which could be applied to children of normal hearing with delayed speech would be a considerable advance.

1 Martin, J. A. M., and Martin, D., British Medical fournal, 1973, 2, 459.

\section{Complaints against Doctors}

The practising doctor is apt to think of himself as being more exposed than most professional men and women to the risk of complaints, accusations, and lawsuits by the people whom he exists to serve, his patients. But this is not how the public see it. To them the medical profession as a whole often seems to be a well-defended fortress affording safe shelter to its individual members. Doctors, they suspect, get their own way too easily. There is some truth in both points of view.

Doctor's themselves are uncomfortably aware that they may be sued in the courts, reported to the General Medical Council, and accused through the disciplinary machinery of the Health Service if, as most do, they work in it. By these processes their employment can be brought to an end and their professional reputation destroyed. It is therefore no wonder they have generally adopted a somewhat defensive posture when Government departments or official reports have called in question the adequacy of the prevailing disciplinary arrangements. These have nevertheless undergone considerable changes over the years-largely with the profession's consent-since Lloyd George introduced (in 1912) the disciplinary machinery that was to become part of the medical scheme set up by the National Insurance Act of 1911. The story of how this machinery has developed, of how the public have used it and what they thought of it, of the responses that doctors have made to attempts at changing it, and of its working today is admirably set out, mainly in the context of general practice, by Mr. Rudolf Klein in a book published this week. ${ }^{1}$

From the Government's point of view the main object of having a disciplinary scheme has been to protect the taxpayers by ensuring that doctors give value for money and do not encourage malingering (Lloyd George's word). ${ }^{1}$ Likewise when the National Health Service was introduced the Gorernment of the day was concerned to prevent abuse of certification. Such matters as the prescribing of expensive drugs in large quantities and the preparations deemed not to be drugs for which the State must pay have furrowed many brows in the committees called to investigate them. But the general public's complaints are on very different grounds. Klein inquired about these from the clerks of executive councils and found that the major cause of complaint today is "the style of general practice." Nearly $20 \%$ of all grumbles were about the manners and remarks of general practitioners. Another $15 \%$ were about the manners and remarks of receptionists. Nearly $15 \%$ were over failure to visit or delay in doing so, and $11 \%$ concerned examination or treatment. About $7 \%$ of the complaints expressed dissatisfaction with appointment systems, and it is worth noting that more than half the clerks of the executive councils said that grumbles about the manners of receptionists were on the increase and more than a third found that complaints about appointment systems were also. These troubles present a distinct contrast with those of National Health Insurance days, when the issuing of centificates and improper demands for fees accounted for a large proportion of the complaints. The emphasis in the complaints nowadays on the style and organization of the general practitioner's work doubtless reflects, as Klein supposes, a variety of contemporary attitudes, among them a deterioration in public manners, a less deferential and more demanding approach by patients, and a certain resentment of that by doctors. To these may be added the inclination of some patients to believe that their doctor ought to be able to give good health and happiness to anyone who eats too much, takes no exercise, smokes 20 cigarettes a day, and has a job of soul-destroying monotony. Rudeness to a sick person is indefensible, but the life style of patients as well as of doctors may make for a troublesome relationship at times.

Here $\mathrm{Mr}$. Klein makes an observation that deserves some thought. General practitioners, as he sees them, are banded together (but he does not labour the point) to rebut grievances about technical competence. But the great majority of complaints are not about that at all. They are, rather, about the way the doctor conducts his practice. Thus in a sense attack and defence have little common ground. Furthermore owing to the successful protective mechanisms, as he believes, which the profession has built up over the years, the unbalanced, obsessional complainant is more likely to penetrate them, however poor the substance of his complaint, than the ordinary rather worried citizen with a genuine grievance. Hence the doctors themselves are dissatisfied with a system that is apt to deter the complainants who would command sympathy and to let through the practised builders of mountains out of molehills. Mr. Klein believes that a permanent Council on the Professions, with its own administrative and research staff, to deal with complaints and abuses, might help to get a fairer hearing for the reasonable layman's voice. And he suggests too that the new Community Health Councils might deal with grievances about manners and organization, if those could be clearly defined.

When he comes to consider professional discipline in its more general context of public accountability Mr. Klein has to face a problem that lies at the heart of professional work in contrast to trade and commerce. A doctor tries to do his best for his patient, but the patient usually cannot know whether he really has received the best he could expect. Generally it is only other doctors, not laymen, who can judge of that. Thus the emphasis the profession itself has laid in recent years on continuing education during professional life and now on exploring various systems of "medical audit" will have far more influence on medical 